\title{
Queer in Sport: A Report About the Case of Tifanny Abreu
}

\author{
Rafael Marques Garcia* and Erik Giuseppe Barbosa Pereira \\ Department of Physical Education and Sports, School of Federal University of Rio de Janeiro, Brazil
}

Submission: October 23, 2019; Published: November 04, 2019

*Corresponding author: Rafael Marques Garcia, Department of Physical Education and Sports, School of Federal University of Rio de Janeiro, Carlos Chagas Filho Avenue, 540, University City, Rio de Janeiro/RJ - Brazil

Abstract

The objective of this report was to describe and analyze the trajectory (insertion, permanence and performance) of athlete Tifanny Abreu in high performance volleyball and her process of resignification in Sports. The methodology was descriptive and qualitative. Through an interview with semi-structured script, transcribed and analyzed through the technique of categorization, we find many difficulties faced by the athlete in her process of insertion, resignification and performance in Sport, due to heteronormative, excluding and sexist precepts that permeate this social phenomenon through multiple facets.

Keywords: Gender; Sport; Transgender people; Queer studies

\section{Introduction}

What sparked interest in conducting the study was the fact that Sport is seen as a social phenomenon that reaches fans and viewers from around the world, widely portrayed by the press through the dissemination of images that impact the reader and practitioners who admire it and identify with the sports modalities. Falling into society as a prominent role, Sport is recognized as a male reserve space, a generalized and generalizing field, marked by gender differences that (re) produce inequalities and which are reinforced due to the wide experience and appreciation of the binary hegemonic division between man/woman, male/female [1]. As with other social practices, it is configured as "[...] a place for knowledge and power disputes that define and delimit normality standards on the appearance of bodies, the exercise of sexuality and experimentation of gender representations".

Several studies have already problematized Tifanny's participation in high performance sports [2-10]. In this scenario, what drew our attention to detail the case of athlete Tifanny Abreu is the representativeness she has as the first Brazilian trans athlete to receive authorization from the Fédération Internationale de Volleyball (FIVB) to perform among women. Aware of the adversity that transgender and / or transgender subjects face in the social molds today, our study was justified by presenting an anthropological understanding of the theme, as well as identifying these manifestations of exclusion, adding positively to the critical studies of Gender, Sexuality and Queer in Physical Education and Sport. The participation of athletes who defy the norms of sport, who are eccentric, dubious, provocative, questioning and decentralized seems to subvert, or even displace, the meanings that are used in the sports sphere and that support their premises according to biological determinism and male/female binarism. This unfolding of new senses and meanings is made possible by the presence of a dissonant body, a body that does not fit the preestablished models and does not seem to have classification in sports practice. This queer corporality, when it moves between sport polarities and is inserted in the modern sport of traditional order, allows the amplification of horizons that deal with the limits of the body, its plurality and ambivalence. Still, it allows us to question the biomedical discourse that distinguishes and hierarchizes subjects in normal and pathological, and which is the basis of the main arguments against the presence/existence/ recognition of queer corporealities [8,9]. Based on these assumptions, we aim, therefore, to describe and analyze, under the queer perspective, the trajectory (insertion, permanence and performance) of athlete Tifanny Abreu in high performance volleyball and its resignification process in sport.

\section{Methodology}

Initially, we did exploratory research on the subject in the literature, as well as approached the news about Tifanny Abreu and her performance in foreign and Brazilian clubs. At this time, we also contacted the player to inform of the study and request her collaboration, receiving it promptly. Methodologically, we chose to conduct a descriptive and qualitative research, 
configuring a case study based on the athlete's Oral History. We have prepared an interview script containing the following questions:

a) Tell us about your personal life story;

b) How do you see your route and how do you recognize yourself today?

c) When did you start to practice sports?

d) How was this insertion?

e) How was your relationship with the family and the social environment in this process?

f) How was your process of identity reframing, both in sports and outside?

g) Did you receive support during this time? How was it?

h) How is the relationship of clubs, fans and media with your situation?

i) Have there been changes in treatment and/or prejudice as a result of your trajectory?

j) What are your personal goals from now on?

k) Do you believe your case can inspire future players?

l) What contribution do you believe to promote in sports?

m) What are the main difficulties that you faced or face?

n) Would you like to make other considerations?

Due to the unavailability of presenting in person due to the schedule of games and training at the time of the interview, the athlete agreed to participate in the study virtually after receiving, completing and returning the Informed Consent Form through digital mail. Thus, the interview was conducted via the Internet, using video connection through Skype software, and recorded through Free Video Call Recorder for Skype. In possession of the recorded interview, all recorded material was transcribed to be analyzed using the content analysis technique. We categorize our findings into large blocks based on the relevance of the athlete's speech, following two steps, as Minayo [11] the first, of an analytical order, was delimited through the establishment of keywords that acted as pillars for conceptual reflections. In the second, of empirical order, we delimit categories of selection, organization and systematization of our interpretations, enriching our analyzes according to data present in the scientific literature. Thus, we categorize all in 7 discussion blocks, as follows:
a) Identifications;
b) Family support;
c) The trajectory in sport;
d) The media, the clubs, the fans;

e) Lgbtophobia;

f) Locker room and;

g) Return to Brazil.

From there, we weave our problematizations together with the data present in the scientific literature. The final research paper contained a total of thirty pages, which motivated us to reorder the discussions and thus make the most of the information and insights that the project promoted. Thus, we divided our discussions into two distinct works that, although similar, were divided into: 1- detailing and analyzing the athlete's personal life trajectory [8] and; 2- describe and analyze her sporting trajectory in high performance volleyball [9]. Still, we use some data to formulate a third text, thus taking maximum advantage of the information obtained in the interview. In this report, we are making the results generally available, since their branching (as done in the making of articles) would exceed the minimum allowable limit for the report's formulation. Also, the athlete's speeches were mostly suppressed here for the same reason, however, they are allocated according to each discussion block in the three final articles produced.

\section{Results and Discussion}

In the transcript of the interview, we had 16 sheets to analyze according to the answers given by Tifanny Abreu. Already mentioned above, we ordered our findings in 7 categories according to the qualitative and quantitative relevance in the athlete's speech, that is, by the amount of times and richness of detail with which they were glimpsed and/or unveiled, as follows:
a) Identifications;
b) Family support;
c) The trajectory in sport;
d) The media, the clubs, the fans;
e) Lgbtophobia;
f) Locker room and;
g) Return to Brazil.

In category 1 Identifications: Tifanny makes it very clear how she likes to be treated through the use of feminine pronouns. Currently, the athlete recognizes herself as a transsexual woman. She reveals that since childhood she felt like a girl. However, reports that only after the use of hormones did your body react physiologically as such, a process that occurred in Europe. Tifanny has always dreamed of owning her own home, being financially self-reliant, and having sex change procedures. For the athlete, having money to meet her own costs would prevent her from hearing any comments about her actions involving biological sex. This thought can be triggered by the greater inclination of transsexuals to situations of extreme social 
vulnerability [12]. Sport in this process was of fundamental importance, because according to the athlete, she was always labeled with pejorative adjectives, but when she became a good player, she acquired more respect and the labels ceased: she was no longer the weirdo, but the good player. In this process, she had to overcome homophobia first and only then start his battle against transphobia. What made her choose to change, however, was not sport, but the social lifestyle. She reveals that she has always been in love with heterosexual men, which caused her great suffering because she was unrequited because they did not recognize her as a woman, a fact that changed after her transition process. This process was not so easy. Tifanny was afraid to suffer from street violence, but always accompanied by her teammates, she encouraged herself and let her hair grow to its first extension. The relationship with team members was not affected, and even improved. Her performance, however, changed: due to the use of hormones, Tifanny had a reduction in explosive strength and impulsion, which, she said, also occurred due to her age. After her mammoplasty surgery, she had a lot of pain, but she adjusted to the way she played and continued her path. In category 2Family support, Tifanny was afraid to reveal her identity when younger, however, decided to do so for her happiness. At birth, she grew up in the small town of Conceição do Araguaia, a small municipality on the border of Pará with Tocantins, until she was 13, and then moved to Goiânia. It has always had the support of the family since childhood. The member who was most present was her sister since her youth, where Tifanny does not hide the emotion when reporting such appreciation. Family support is of fundamental importance in these cases; however, we rarely find positive reports involving transsexuals and their families. Situations involving the theme sometimes require breaking emotional ties between family members, in addition to feelings of fear and rejection by transgender subjects [12]. In category 3The trajectory in sport, Tifanny says she always practiced a lot of physical activity. In childhood, she reveals that she always played everything, even in school PE classes. Accompanied by her sister, she was always present in football, basketball and other school games without any reprisal. Tifanny still claims to have good genetics for the sport, after all has always been a good player of the sports she was playing. However, it was in volleyball that she was able to gain a foothold, since football was very exclusionary and prejudicial to her because of her then homosexuality. [13] volleyball presents itself as a space made up of female and homoerotic sociability, favoring the manifestation of alternative masculinities by allowing displacements and transitivities between what is considered masculine and feminine: in common sense, "[...] volleyball is framed as a sport for homosexuals, a fagot sport" [14]. The case of Tifanny, who since the beginning of 2017, has defended the Italian team Golem Volley, made her the first Brazilian trans athlete to perform in high performance volleyball, which attracted the attention of the Brazilian media, further feeding the discussions. on the fertile terrain of volleyball that enables the deterritorialization of sporting conventions, the experimentation of alternative corporealities, the dislocation of hitherto unquestionable knowledge and the broadening of horizons of physical and bodily practices. When she entered volleyball, Tifanny, still male, was discredited for being too feminine. She constantly heard that she would not go forward because she was "very fussy" and late in the sport. Such denunciative speech corroborates the assertion that the sporting world, as well as its managers and actors are still very hostage to sexist and exclusionary standards regarding male and female binarism, coming to disregard the other bodies present, which end up having no space [15].

Such denials, however, gave Tifanny strength to move steadily toward her goal, where she reached the level of professionalism. Along the way, she reveals that some of the promising athletes didn't even get out of the base categories, and those who did didn't make it to the same level of prestige as her own. Your volleyball maintenance process was not easy. Constantly the main target on the court due to her sexuality, Tifanny had to fight her feminine side during the game. Although always focused, other players still presented themselves, such as her physical size - thin and not so high for the male suit - and her gender performativity within the courts, which dissociated the athlete's sex and gender. Tifanny's performativity, while acting in the male suit, admits shifts in the senses of sport, since it disarticulates signs, symbologies and meanings that are expected of the male athlete. Acting in a "feminine" way, in that context, seemed to make all the athlete's talent and potential invisible, which needed to prove, albeit not so emphatically, a certain degree of masculinity. The absence, or even secondary participation of male attributes, aroused an inability to rise in sports career, which occurs, according to Tamagne [16] because homosexual athletes are interpreted as having a tiny, failed, insufficient virility, not corresponding to the levels minimums that are required for the universe of sport, recognized as the male reserve area and, therefore, of protruding classical masculinity.

Tifanny, male, played in the years 2007 and 2008 for Foz do Iguaçu, where she was featured in the Brazilian Superleague. In 2008, she went to play in the Portuguese league and from there she never stopped: in 2009 she moved to Spain, then France in 2010, returned to Portugal, went to Indonesia. In the latter country, however, I was already tired of volleyball. Her greatest desire was to become a woman, which she said was past time. Her transfer to Belgium took place in 2012, where after falling in love with a player, she began her transformation. Now definitely Tifanny, played in the Netherlands, returned to Belgium and remained there until 2016 defending a men's third division team that gained access to the second in the local competition. At this point in her life, she claims to have done all the hormonal treatment. At the same time, the athlete also participated in the European gay tournaments, including Eurogames and Gay Games. She claims to be well known and considered queen by the other homosexuals, but according to her it only happens because she plays well. 
At the time of the interview, Tifanny was still performing in Belgium among men. When asked about her willingness to play with women, she was emphatic that at first, she never considered this idea because it was forbidden to her, but when an entrepreneur told her she could help in this process, the athlete began to think about the possibility. Tifanny said she was not concerned about the criticism that might arise. According to her, dealing with criticism is commonplace in her life, and she needs to think about her financial side and career opportunities. Now a member of the Volleyball Bauru team, from the interior of São Paulo, the athlete stands out inside the courts for her skill, but also outside them for the discussions, decentralizations and reflections she promotes to the sport in general. Vigarello [17] states that corporeal metamorphosis challenges the gender norms that govern sport in a process called feminization of virility and masculinization of delicacy, opening doors for the reinvention of traditions and differences as well as their insertion in this scenario. Transsexuality in sport materializes something previously unimaginable, which transcends the ability to understand the aspects that underpin this global phenomenon. The trans athlete's performativity enables the emergence of practices and understandings contrary to gender norms, making explicit the exclusionary character of binary identities and denying the explanatory precedence of the biomedical order [18]. We can understand them, therefore, as resulting from postmodernity, "[...] since they evoke an undefined state of questions and problems, which cannot be answered in the current sports system standardized by heteronormative logics" [19]. In category 4- The media, the clubs, the fans, Tifanny states that the press leads the opinion of the people. She complains about the way soap operas approach transsexuals on their show. The fact saddens her. For her, people who do not know a transsexual support the idea that this guy is "[...] a effeminate and crazy gay". Still, many views them as men or gay, not respecting dissonant and / or non-binary gender identities. The athlete states that this thought extends even to the sports media, stating that this instance proves to be ignorant about the subject.

Studies on "Gender, Media and Sport" point to a different treatment between the representation of men and women. Portraying queer bodies or competitions does not seem to attract the attention and gaze of media artifacts [19], contributing to the invisibility, silencing and seclusion of these expressions in the sporting environment, which contributes to legitimize and crystallize the heteronormative precepts that permeate the sports organizations [2]. The factor of recognition becomes crucial not only in the media, but also among the clubs in which Tifanny has been circulating. According to the athlete, because they know her and live together, they always provided her with the necessary support through love, adoration and respect. This evidence is even supported when extended to the crowd. Tifanny says she has never heard of any offense in Europe during the games. She states that the most that happens is a strangeness of children, who are confused to see a woman among men, as well as expressions of surprise on the part of the fans. Although the behaviors of estrangement are triggered by Tifanny's corporeality, she claims she has never received offenses acting on the European continent. Even if she heard such fears, Tifanny says she wouldn't mind, because for her the role of the fans is to provoke and try to destabilize the player. However, it states that it would not accept the same kind of conduct off the court. In Category 5- Lgbtphobia, Tifanny claims to have never suffered any aggression of any kind while in Europe. She says that people, including children, are super respectful and always treat her as a woman on and off the court.

The athlete even mentions that after the games there are always jokes between the athletes of the teams, but none of them has lgbtphobic nature. Tifanny is still speaking about three cases that headlined the topic: Lilico, Alessia and Michael. She is incisive when commenting on the cut of the Brazilian team suffered by Lilico. For her, the fact that the athlete was declared homosexual compromised the way he was viewed, which would give him the label "The Lilico Player, such number of Brazil, gay ...". The same thought extends to the case of transgender player Alessia and the complaints that are manifested due to her participation. In the case of Michael, Tifanny says that the athlete should not have listened to the fans, because the role of this was to destabilize him. For her, it is common homosexuals to hear insults from the stands in Brazil, but this is just an attempt to get the player out of the game. Studies that focus on homophobia in sport generally explore how it is triggered through modalities both on and off the court, as well as outside. [20] states that homophobia is institutionalized in sports due to the discourses that were established to build it, that is, based on the classical masculinity model that privileges the participation of "men with capital M". In this imaginary, male homosexuality would direct gay athletes into physical and emotional disqualifications, culminating in the unworthiness of staying and belonging in the temple of sports practice $[14,16]$. [1] bring to light another type of phobia stemming from the participation of MMA trans fighter Fallon Fox: transphobia, which in short, maintains the same linearity as above: aversion and repulsion to those who subvert gender normalization and of sexuality. Soon, "[...] homophobia and transphobia easily emerge in situations in which the body gendersex-desire linearity is deconstructed, whether in the sports field or out of it."

Understanding lgbtphobic manifestations in sport is a complex exercise that demands numerous semantic and polysemic factors. It is up to us to reflect, therefore, that the institutionalization and naturalization of discriminatory processes in sports spaces are close to other forms of prejudice and moral and physical aggressiveness that erupt in these territories. Understanding how these processes legitimize themselves is fundamental in order to envision new ways of interpreting these occurrences as broader social phenomena 
and present in layers other than those related to Sport [8]. In the 6- Locker room, Tifanny says that both masculine and feminine serve her, however, emphasizes the preference to enter the masculine, if she does not show her body to the other companions, being a matter of respect that is tied to the social moralism. The athlete says that in Europe she feels safe to do so, because her colleagues accept without any problem, which would not happen in Brazil: "Ah, in Brazil they would rape me inside the bathroom, you know." This problem stems from the way bathrooms and changing rooms are separated. Through the distinction by sex, the concept of public and private isolation between men and women is established, so that the space destined for them is a temple of femininity, while the former is the public place for unloading and / or manifestation. of his manly and hegemonic nature. Thus, the locker room acts as body regulator and maker of subjectivities concerning the heterosexual world [21].

In any case, Tifanny shows a certain insecurity as she cannot enjoy the space in the same way - or other desirable ones - as her colleagues, still carrying a mix of doubts about the harassment that may occur through the fantasy / materialization relationship. driven by the locker room space. And in category 7- Return to Brazil, Tifanny was afraid because the country is not yet receptive to trans people. The athlete's fear is supported by alarming indications of violence against LGBT subjects in Brazil. Although the scenario is not the best, Tifanny was excited about the possibility of acting in Brazilian lands and says between laughs: “[...] if you pay me, I'll be beautiful!”. However, she recognizes that it would only come after its transition and to act professionally. The athlete also says that would not be well accepted by the other teams and their fans, but that their concern is only with the team that pays her at the end of the month. Finally, she argues that the repercussion of her case would be a breach of the considerable social paradigm, stating that it would occur in different ways if it acted in the feminine or masculine: in the first suit, there would be so much strangeness because the level of the other players would be equivalent to her and she would be recognized for her talent, but in the second Tifanny would draw more attention for her feminized body among other men.

In 2017, Tifanny ended her resignification process, receiving authorization from FIVB to play in women's volleyball. She was hired by the Italian team Golem Volley, competing in the Serie A2 of the Italian league. After the competition ended, she returned to Brazil and joined the training team of the Bauru Volleyball team to reestablish and recover physically after surgery on her left hand. On December 5, 2017, she was officially hired by the team and her debut took place five days later, the 10th, in a match valid for the $2017 / 2018$ Superliga of the national volleyball elite, against the team of São Caetano, which won the duel by 3x2. Tifanny's participation has become a milestone for Brazilian volleyball, rekindling the discussions about queer in sports, vigorously destabilizing the heteronormative structures and premises that permeate this field and devising new horizons and (re)meanings of corporeality in practice. modern physical and sporting

\section{Conclusion}

We infer that Tifanny Abreu's trajectory in sports is closely linked to personal and social factors. The path taken to attain the status of representativeness and prestige that it exercises today proves to be unharmonious, full of barriers, obstacles and reluctances. Were it not for the willpower and ambitious profile of the athlete, allied to the opportunities and conditions necessary for this event to consolidate, we would hardly be discussing the effective participation of transsexuals in Brazil's high sports performance and which developments are possible from this conjecture? Tifanny's ancestry as a trans athlete in volleyball carries with it many oppressive and recriminatory processes, but also the recognition and legitimacy of her corporeality in the space in question. Even though this modality is notably recognized as a larger space for homosociality and better absorption of dissonant manifestations of heteronormativity $[13,22]$, it is still immersed in the supreme universe of sport, which is very resistant to subversion and reexamination of its classical, longitudinal values. and thunderstorms.

The presence of homosexuals - a queer portion - is provocative, but when we have the transsexual insurgency another queer portion - the disturbances are even greater, perhaps because in the former, some linearity can still be identified. between sex and gender, a relationship exemplified through cisgenerity, which in the case of transsexuals presents ruptures and resignifications, becoming even more emblematic, challenging and problematizing the phenomenon of sport. Thus, even in the queer universe of sporting corporealities, it is possible to identify new postulations of power, privileges, disparities, recognitions, valuations and symbolisms which, it seems, continue to legitimize symptoms of compulsory heteronormativity through classifications, certifications, territorializations, borders. and hierarchical and power differences between queer subjects themselves. Finally, it is noteworthy that, although Tifanny's case can be identified here and considered as suffering, but overcome, we do not deny the multiplicity of plots that can unfold in the sporting trajectory of queer athletes in varied contexts and scenarios, seeing countless and endless possibilities for realization beyond forced romanticization of overcoming and self-realization.

\section{References}

1. Grespan CL, Goellner SV (2014) Fallon Fox: The Queer Body in the Octagon. Movement 20(4): 1265-1281.

2. Brito LT, Pontes VS (2015) Tifanny Abreu is still one of the guys -a discussion about transgenderity in volleyball space. In: Brazilian Congress of Sport Sciences and Vi International Congress of Sport Sciences 1(28): $1-16$.

3. Coelho RT (2018) Transgender athletes: taboo, representativeness, minorities, and sports sciences. Journal of Academic Papers Universe 3(5): 29-58. 
4. Paes EA, Moas LC (2018) The masculine, feminine and sport - the João Nery bill and a look at volleyball player Tiffany. Transversos Magazine 14: 133-149.

5. Prado VM, Nogueira ALGA (2018) Transsexuality and sport: The Tiffany Abreu case in "game". Electronic Journal Social Interactions 2(1): 60-72.

6. Rezende RM, Passos A (2018) The Lies That Told You About Tiffany's Presence in the Superleague.

7. Botelho JG, Aguiar TG0, Square RP (2019) Problematizing gender issues: "The strength of a strong woman". Latin American Journal of Studies in Culture and Society 5: 1-9.

8. Garcia RM, Pereira EGB (2018) Reframes in Sport through the performance of Tifanny Abreu. Electronic Journal of the Graduate Program of the House of Representatives 11: 24-44.

9. Garcia RM, Pereira EGB (2019) Tifanny Abreu's personal career in high performance sport. Movement 25(1): 1-15.

10. Silva MEA (2019) The division in sport should be separated by gender or gender. Teaching and Cyberculture Magazine 3(1): 236-249.

11. Minayo MCS (1998) The knowledge challenge: qualitative research.

12. Benedict B (2011) At school you learn that difference makes difference. Feminist Studies Journal 19(2): 549-559.

13. Coelho JAG (2009) Volleyball: a hybrid space of sports sociability. In: Toledo LH, Costa CE (Eds.), Game vision: anthropology of sports practices. São Paulo: Third Name Publisher.
14. Angels LA (2015) Men's volleyball are for men: representations of the homosexual and the supporter on an episode of homophobia. Movement 21(1): 11-22.

15. Camargo WX, Kessler CS (2017) Beyond the male / female: gender, sexuality, technology and performance in sport from a critical perspective. Anthropological Horizons 47: 191-225.

16. Tamagne F (2013) Homosexual mutations. In: Courtine JJ (Orgs). Manhood History: Manhood in Crisis? XX-XXI centuries. Petrópolis, RJ: Voices 3: 424-453.

17. Vigarello G (2013) Sports virilities. In: Courtine JJ (Orgs). Manhood History: Manhood in Crisis? XX-XXI centuries. Petrópolis, RJ: Voices 3: 269-301.

18. Butler J (2015) Gender problems: feminism and subversion of identity. ( $8^{\text {th }}$ edn), Rio de Janeiro: Brazilian Civilization, p. 236.

19. Camargo WX, Rial CSM (2009) LGBT Sport and Postmodern Condition: anthropological notes. Interdisciplinary Research Books in the $\mathrm{Hu}$ manities 10(97): 269-286.

20. Anderson E (2005) In the game: gay athletes and the cult of masculinity. New York: State University of New York.

21. Camargo WX (2014) Ethnographic notes about changing rooms and the eroticization of sports spaces. Artemis Magazine, 17(1): 61-75.

22. Brito LT (2018) Masculinity statements in narratives of young volleyball athletes: readings in queer horizon. Thesis (PhD in Education) State University of Rio de Janeiro, Education University, Rio de Janeiro, RJ.

\section{Your next submission with Juniper Publishers will reach you the below assets}

- Quality Editorial service

- Swift Peer Review

- Reprints availability

- E-prints Service

- Manuscript Podcast for convenient understanding

- Global attainment for your research

- Manuscript accessibility in different formats

( Pdf, E-pub, Full Text, Audio)

- Unceasing customer service

Track the below URL for one-step submission

https://juniperpublishers.com/online-submission.php 